\title{
Short-Pulse Laser Sintering of Multilayer Hard Metal Coatings: Structure and Wear Behavior
}

\author{
Evgeny Kharanzhevskiy • Alexey Ipatov • \\ Irina Nikolaeva $\cdot$ Raushaniya Zakirova
}

Accepted: 6 February 2015 / Published online: 14 February 2015

(C) Springer New York 2015

\begin{abstract}
This paper reports on the phase composition and properties of multilayer hard metal coatings deposited on steel by a process variant of Selective laser melting (SLM). The process is based on layer-wise short-pulse laser sintering of high-dispersive WC-Co powder on a steel substrate. High temperature in the molten zone and chemical interaction with the substrate explain high level of adhesion strength between the coating and the substrate. The technique allows obtaining both high quality hardmetal multilayer gradient coatings with thickness up to $200 \mu \mathrm{m}$, density near to the theoretical density (TD), hardness up to $21 \mathrm{GPa}$ and complex 3D objects by layer-wise powder based process such as SLM.
\end{abstract}

Keywords Selective laser melting $\cdot$ Gradient coatings $\cdot$ Hard metal $\cdot$ Hardness $\cdot$ Abrasive wear resistance

\section{Introduction}

Protective coatings based on hard metal powders meet increasing requirements for commercial applications. This explains considerable interest in scientific researches on the formation of hard coatings on the surface of steels. Coatings properties should be carefully gauged in terms of its specific working conditions. Lakhothin et al. (2009) [1] have shown that choice of a technique for coating deposition should be based on required thickness, hardness, adhesive strength and microroughness. Modern physical vapor deposition (PVD) techniques provide thin (a few microns) coating layers with high hardness. They are mostly used to improve performance of cutting tools. Savarimuthu et al. (2001) [2] described that unlike PVD methods, gas-thermal techniques allow deposition of thick layers (over $100 \mu \mathrm{m}$ ), where hard particles of tungsten carbide are binded by low-melting particles (usually $\mathrm{Co}$ and $\mathrm{Ni}$ ). Chemical vapor deposition (CVD) methods are based on chemical reactions or decompositions of

E. Kharanzhevskiy $(\bowtie) \cdot$ A. Ipatov $\cdot$ I. Nikolaeva $\cdot$ R. Zakirova Udmurt State University, 426034Universitetskaya st., 1, Izhevsk, Russia e-mail: eh@udsu.ru 
components directly on the deposited surface and used for the rapid production of coatings on parts with complex geometry. CVD methods allow producing high quality coatings which do not require finishing. Among significant problems of described methods are low adhesive strength and high operating temperature up to $600{ }^{\circ} \mathrm{C}$.

A problem of the low adhesion strength between the coating and substrate may be solved by applying a concept of gradient coatings, wherein there is a gradual change of properties over the thickness of the coating. Softer inner layers may provide better adhesion strength, whereas harder outer layers ensure high durability. A technology which has the possibility for creating such gradient coatings might be based on Selective Laser Melting (SLM) or laser cladding of metal matrix composites (MMC). SLM as one of rapid prototyping technologies is suitable for making 3D parts layer-wise directly from metal powders and potentially can be used to produce 3D hard metal functional parts from commercially available powders. The main disadvantage of SLM related to hard-metal parts is high level of porosity [3]. Porosity can be reduced by impregnation of the sintered hard metal parts by a bronze alloy, but according to investigations in this area performed by Maeda and Childs [4] impregnation does not lead to satisfactory abrasive wear resistance in compare to full density hard metal parts produced by powder metallurgy.

Laser sintering of preplaced powders has a lot in common with laser cladding of MMC. In a study, performed by Dubourg and St-Georges [5], coatings were made from a nickel-base matrix and WC with a volume fraction of $50 \%$. Authors of the study investigated the influence of the laser cladding parameters in $\mathrm{CW}$ mode on the geometry and composition of MMC coatings. In laser cladding of MMC the fraction of hard metal phase dispersed in metal matrix usually does not excess $50 \mathrm{vol}$. \%. Techel at al. [6] studied coatings microstructure and established the influence of partial carbide dissolution and formation of new hard phases on the hardness and wear behavior. High energy input during laser processing can lead to excessive heating of WC particles to forming brittle phase, which is drawback for MMC coating [7]. Thick WC-Co coatings can be deposited by thermal spraying as High Velocity Oxygen Fuel (HVOF), detonation spraying and also using direct metal deposition [8].

Comparing to powder metallurgy, laser sintering has much lower exposure time of local volumes at high temperatures, so the high density of hard metal parts might be achieved by steep increase in the temperature only. Unlike CW mode, lasers operating in short pulse mode can generate much higher peak power density of the order of $\mathrm{GWcm}^{-2}$ because the energy of a pulse is emitted over a short duration. The resulting effect on the material is instantaneous melting, vaporization and ionization of the expanded gas. The short pulse time and plasma generation lead to appearance of a heat-sustained shock wave that moves radially outwards from the interaction cite. The high pressure behind the shock wave exerts a comprehensive force on the material, known as evaporation recoil force. This compressive force has been shown by Morgan et al. [9] to result in modification of the melt pool shape, resulting in increasing of the material density. The authors also studied the effects of Q-Switch pulsing frequency, scanning speed and scan spacing on density of $316 \mathrm{~L}$ stainless steel cubic primitives. So the use of a short pulse laser in SLM of hard metal alloys can potentially increase the density and functional properties of sintered layers.

This paper reports on the phase composition, density, hardness and abrasive wear resistance of thin multilayer hard metal coatings deposited on steel by a short pulse laser sintering. The coatings were characterized with the use of optical, XRD and SEM 
methods, measurements of the density, hardness and abrasive wear resistance tests at different conditions.

\section{Experimental}

\section{Experimental Set-up}

The experimental facility consists of an ytterbium fiber laser and a process chamber with controlled atmosphere. The chamber is initially evacuated by a backing pump and then filled with high purity argon at the pressure of 1.05 bar. The laser has maximum power of $50 \mathrm{~W}$ operating in a short pulse mode with the wavelength of $1.065 \mu \mathrm{m}$ and the pulse repetition frequency in the range from 20 to $100 \mathrm{kHz}$. The powder feeding system allows building multi-layer coatings, but the microstructure and properties analysis was performed after deposition of each layer of the multilayer coating. A commercially available WC-20 wt.\% Co mixture with an average grain size of $1 \mu \mathrm{m}$ and an apparent density of $3.4 \mathrm{~g} / \mathrm{cm}^{3}$ was used as powder. The thickness of powder beds was set to $60 \mu \mathrm{m}$.

\section{Energy Characteristics and the Scanning Strategy of the Laser Sintering Process}

The laser chosen for laser sintering process has a pulse time of about several tens of nanoseconds which is much longer than the relaxation time for energy transfer from gas of valence electrons (which absorbs laser energy) to lattice of metal parts. So the action of laser energy on powders can be described mainly by thermal mechanism, but the pulse time is short enough to ensure the high rate of heating (about $10^{7} \mathrm{~K} / \mathrm{s}$ ) and high temperature gradient $\left(10^{7}-10^{8} \mathrm{~K} / \mathrm{m}\right)$ in the treated zone. These parameters were established by Kharanzhevskiy and Krivilyov [10]. The variation in process parameters had a significant effect on the material density. The influence of the pulse repetition frequency, scan speed, scan spacing and scan strategies on the density of multilayer coatings was investigated to obtain the optimal process parameters of laser sintering. Results of that preliminary study are summarized in paper [11]. It is shown that density and roughness of sintered layers can be improved by an appropriate choose of the processing parameters, which minimizes 'balling effect' and distortions due to thermocapillary forces which is good for post-processing. This work aims to study the phase composition and functional properties throughout a coating, composed of multiple layers with a number from 1 to 10 .

The coatings were produced with the parameters listed in Table 1. The power was kept at the maximum value of $50 \mathrm{~W}$ at the pulse repetition frequency of $100 \mathrm{kHz}$. The laser beam was focused in a spot with the diameter of $30 \mu \mathrm{m}$. By the computer simulation of heat transport in porous media [12] it was established that such energy characteristics lead to local overheating of the powder bed up to the melting point of tungsten carbide $\left(2870{ }^{\circ} \mathrm{C}\right)$. Due to the high temperature gradient in the irradiated area, a thin layer of the steel substrate with a thickness $10-30 \mu \mathrm{m}$ has been melted. That makes the conditions of active mixing in the molten zone which lead to chemical interaction between tungsten carbide and iron and provides better adhesion strength between the coating and substrate. 
Kruth et al. [13] found that both the appropriate process parameter adjustment and the application of special scanning strategy influence on resulting roughness, microstructure, density and mechanical properties. Our preliminary study [11] has shown that the best result in those terms was observed when an O-type scanning strategy which is shown in Fig. 1 was applied. The scanning speed of the laser beam $V_{b}$ is in the fact the velocity of the beam motion along the circle of O-type track in Fiq. 1. When the resulting scan speed $V_{S}$ over the y-axis was $20 \mathrm{~mm} / \mathrm{s}$ a laser-spot overlapping was characterized by the value of $70 \%$ in x-direction and $53 \%$ in y-direction. The scan spacing value $Z$ is defined here as the distance between consecutive O-type tracks scanned by the laser. The scan spacing $Z$ was chosen as a fraction of the width of the track. The width of the track was fixed in this study at the value of $200 \mu \mathrm{m}$. The complex motion of the laser beam with the beam speed of $0.9 \mathrm{~m} \mathrm{~s}^{-1}$ was performed by a scanning head with the use of integrated scanning mirrors. The scan speed $V_{S}$ was set by the definite shift between consecutive rings of O-type track.

\section{Wear Tests of WC-Co Coatings}

The wear resistance of the WC-Co coatings (with 4 sintered layers) has been measured using two-pin pin-on-disk tribometer at different load conditions: (A) - in case of insufficient lubrication. The lubrication was filled with $50 \mathrm{vol} \%$ of alumina with the average grain size $5 \mu \mathrm{m}$; (B) - in case of dry abrasive wear with silica sand abrasive which particles have the average size of $150 \mu \mathrm{m}$. The total load was $10 \mathrm{~kg}$, giving a nominal contact pressure of $0.8 \mathrm{MPa}$. Number of loading cycles was $1 \cdot 10^{5}$ at the friction speed of $35 \mathrm{~m} / \mathrm{min}$.

\section{Results}

\section{Microstructure Analysis}

The results of X-ray diffraction study of coatings with different number of sintered layer in range from 1 to 10 are shown in Fig. 2. The diffraction patterns of WC-Co powder and steel substrate are also included in the plot. Figure 2 clearly shows deep changes in the phase composition of sintered coatings from layer to layer. Diffraction pattern taken from the first sintered layer (curve 01 in Fig. 2) demonstrates the high amount of alpha and gamma phases of iron. Peaks of these phases are more intense in compare to the peaks of $\mathrm{WC}$ and $\mathrm{W}_{2} \mathrm{C}$ phases. Quantitative phase analysis of all the diffraction patterns was performed with the use of the Rietveld refinement method. According to the results, presented in Table 2, the first sintered layer has amount of iron phases about $80 \%$ which is higher than the value obtained from SEM investigation. Xray energy-dispersive microanalyses (EDS) gives the following concentration of elements on surface of the first layer: Fe-66; W-25; C-7; Co-2 wt.\%. The overstated value of alpha-iron, obtained by XRD study, may be caused by a relatively small thickness of layer which results in penetration of X-rays into substrate giving influence on the result of the quantitative analysis. It is also should be noticed that EDS-analysis gives a surprisingly low content of cobalt in coatings. Absence of cobalt may be explained by the steep difference in the melting point of WC in compare to Co. Actually, the melting 
Table 1 Parameters examined for production of coatings

\begin{tabular}{ll}
\hline Parameter & Examined values \\
\hline Power $(\mathrm{W})$ & 50 \\
Beam speed $V_{b}\left(\mathrm{~mm} \mathrm{~s}^{-1}\right)$ & 900 \\
Scan speed $V_{S}\left(\mathrm{~mm} \mathrm{~s}^{-1}\right)$ & 20 \\
Scan strategy & O-type \\
Scan spacing $Z(\mu \mathrm{m})$ & 200 \\
Pulse frequency $(\mathrm{kHz})$ & 100
\end{tabular}

point of $\mathrm{WC}\left(2870{ }^{\circ} \mathrm{C}\right)$ is comparable to the boiling point of cobalt $\left(2927{ }^{\circ} \mathrm{C}\right)$ which leads cobalt to evaporate actively.

The diffraction patterns of all sintered layers have also peaks corresponded to $\mathrm{W}_{2} \mathrm{C}$ cubic and hexagonal phases and traces of $\mathrm{Fe}_{3} \mathrm{~W}_{3} \mathrm{C}$ phase. Their appearance indicates high temperature thermal decomposition of tungsten carbide corresponding to the reactions

$$
\begin{aligned}
& 2 W C \rightarrow W_{2} C+C, \\
& W_{2} C \rightarrow 2 W+C,
\end{aligned}
$$

and chemical interaction with Fe.

The increase in the number of sintered layers leads to the steep increase in quantity of tungsten carbide phases. As it shown in Fig. 2 and Table 2, after the 3rd sintered layer, $\alpha$-Fe has only traces on diffraction patterns. The EDS-analysis confirms that result. The concentrations of elements on the surface of the fifth sintered layer are: Fe5; W-75; C-13; Co-4 wt.\%. After the fifth sintered layer the phase composition of coatings seems to be independent from the number of layers so after that point the coatings have stable phase content which fully consists from carbide phases.

The results of SEM-investigation of coatings lead to the following implications. Firstly, they show good quality of the coating with low amount of pores. Secondly, they enlarge the results of X-ray diffraction study that layers have a gradual changing in the phase composition from layer to layer as it was shown above. In Fig. 3 a a general view

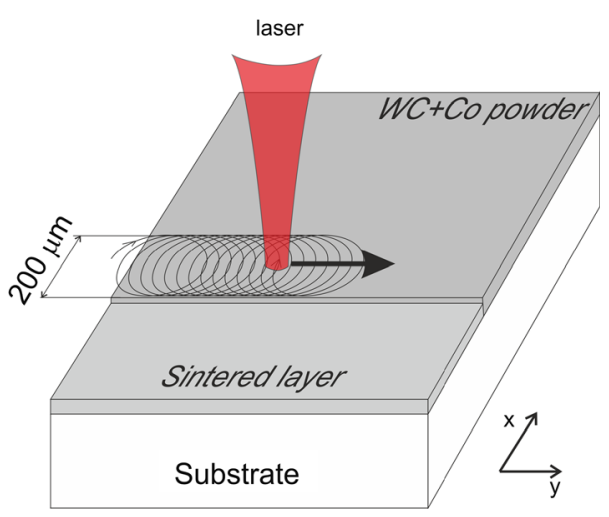

Fig. 1 The scanning strategy 


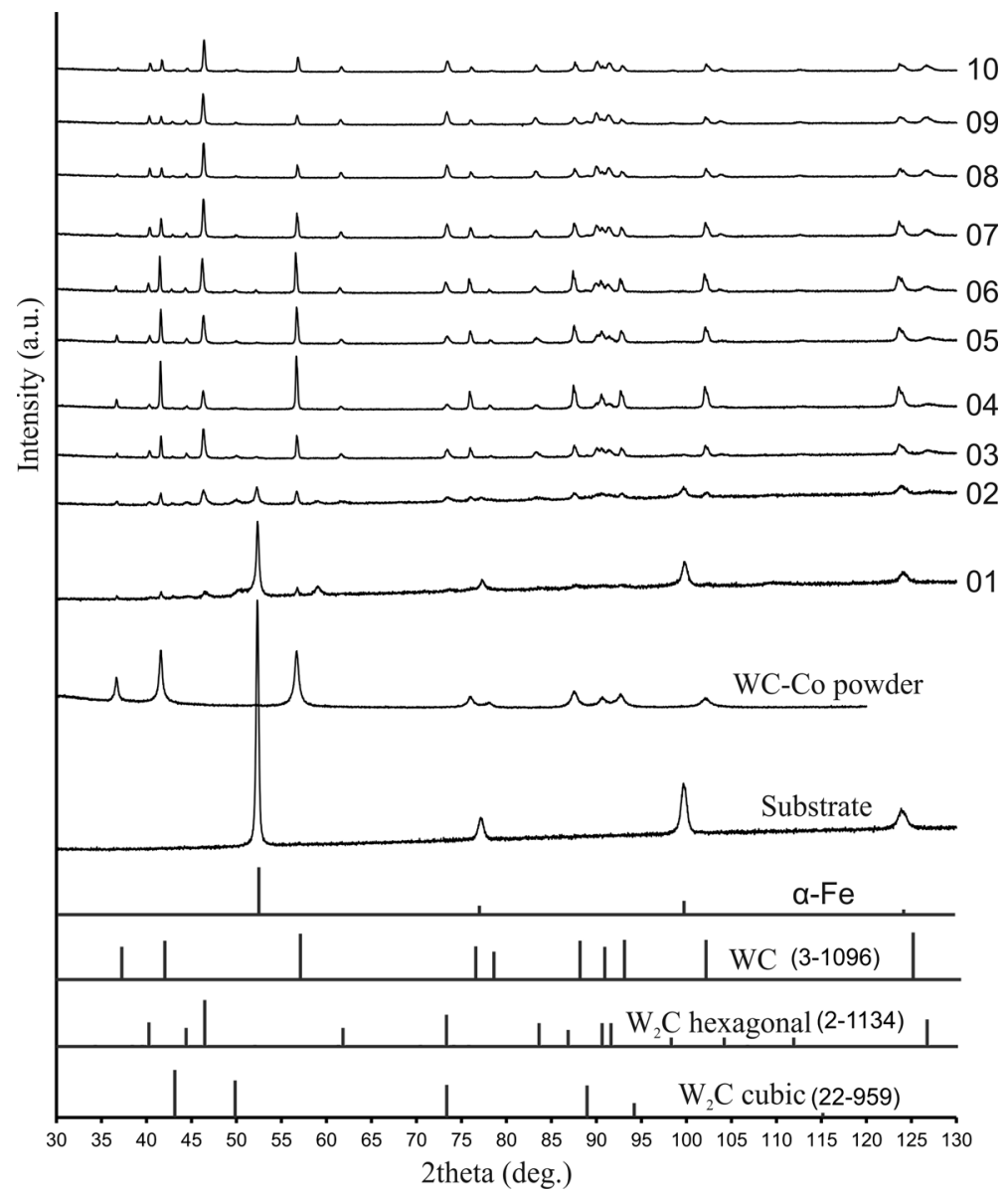

Fig. 2 Results of XRD study: the substrate, the WC-Co powder and sintered layers. Digits on the left of diffraction patterns correspond to the quantity of sintered layers of the multilayer coatings (JCPDS card numbers of phases are in brackets)

of the single layer coating is shown, wherein traces of the laser beam movement are clearly visible. Cylindrical-shape pores are rare and take not more than $1 \%$ of the coating surface area. In Fig. $3 b$ the surface area near a pore is shown in the phase contrast mode (by back scattering electrons). According to EDS-analysis light areas mainly consist from tungsten and carbon atoms whereas dark gray areas have about 70 wt.\% of iron. The dark areas also contain large amount of needle shape microcrystallites which indicates high temperature in the irradiated area that is more than the melting point of iron during laser sintering process.

The increase in the quantity of sintered layers leads to the increase in porosity and microcracks appearance. Figure 4a shows the SEM-image of the surface after sintering of the fifth layer where several microcracks can be seen which formed due to the thermal stresses. The area of the surface near one of them is shown in Fig. 4b with higher magnification. In this area the large amount of the cubic-shaped crystallites are visible that can belong to a tungsten carbide phase only, which indicates extremely high temperature over the melting point of the tungsten carbide, formed during laser short 
Table 2 Thickness, phase composition (wt. \%) and theoretical density (TD) of multilayer hard metal coatings versus the number of sintered layers

\begin{tabular}{llrllllll}
\hline Number of layers & Thickness, $\mu \mathrm{m}$ & $\mathrm{WC}$ & $\mathrm{W}_{2} \mathrm{C}(\mathrm{hex})$ & $\mathrm{W}_{2} \mathrm{C}(\mathrm{cub})$. & $\mathrm{Fe}_{3} \mathrm{~W}_{3} \mathrm{C}$ & $\alpha$-Fe & $\gamma$-Fe & $\mathrm{TD}^{\mathrm{a}}, \mathrm{gcm}^{-3}$ \\
\hline 1 & 21 & 8 & 9 & 3 & 1 & 63 & 16 & 9.6 \\
2 & 39 & 19 & 24 & 4 & 4 & 42 & 7 & 12.1 \\
3 & 54 & 39 & 48 & 7 & 2 & 4 & 16.1 \\
4 & 66 & 67 & 28 & 3 & 2 & & 16.0 \\
5 & 74 & 53 & 38 & 5 & 2 & 2 & 16.1 \\
6 & 91 & 48 & 39 & 9 & 2 & 2 & 16.2 \\
7 & 109 & 41 & 48 & 11 & & & 16.6 \\
8 & 137 & 32 & 57 & 10 & & 1 & 16.7 \\
9 & 167 & 27 & 56 & 14 & 3 & & 16.6 \\
10 & 195 & 39 & 50 & 8 & 3 & & 16.4 \\
\hline
\end{tabular}

\footnotetext{
${ }^{\mathrm{a}}$ by XRD phase composition
}

pulse processing. So the proceeding technique used in this study might be categorized as a Selective laser melting (SLM) method.

Results of density measurements are shown in Fig. 5. It is clearly seen that the increase in the coatings thickness influences the density. As it follows from the XRD phase analysis the decrease in the density of multilayer coating comes along with reducing the iron content in layers up to 4th sintered layer. After that point the phase composition became more or less stable which stabilizes the density of coatings at value of about $70 \%$ TD. So we can conclude that gradual changes in the phase

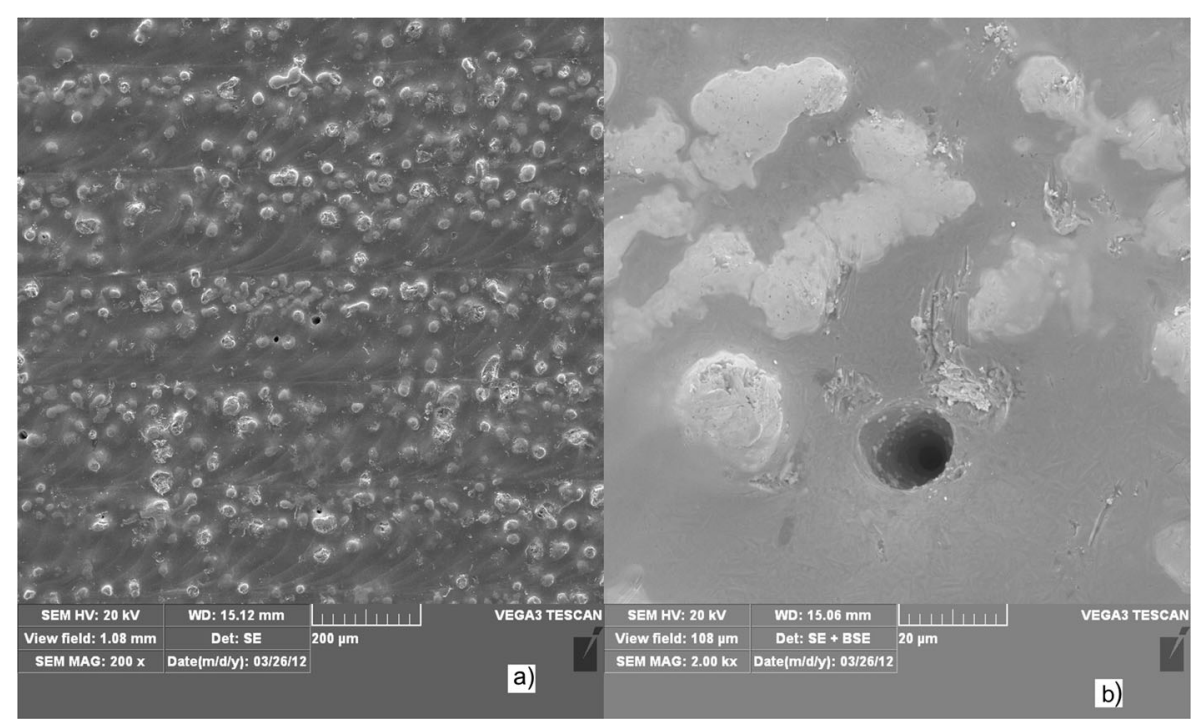

Fig. 3 SEM-micrograph images of the first sintered layer: (a) - the visual image of the surface in secondary electrons (SE); (b) - the composited image of the surface near a cylindrical pore in SE and back scattering electrons (BSE) 


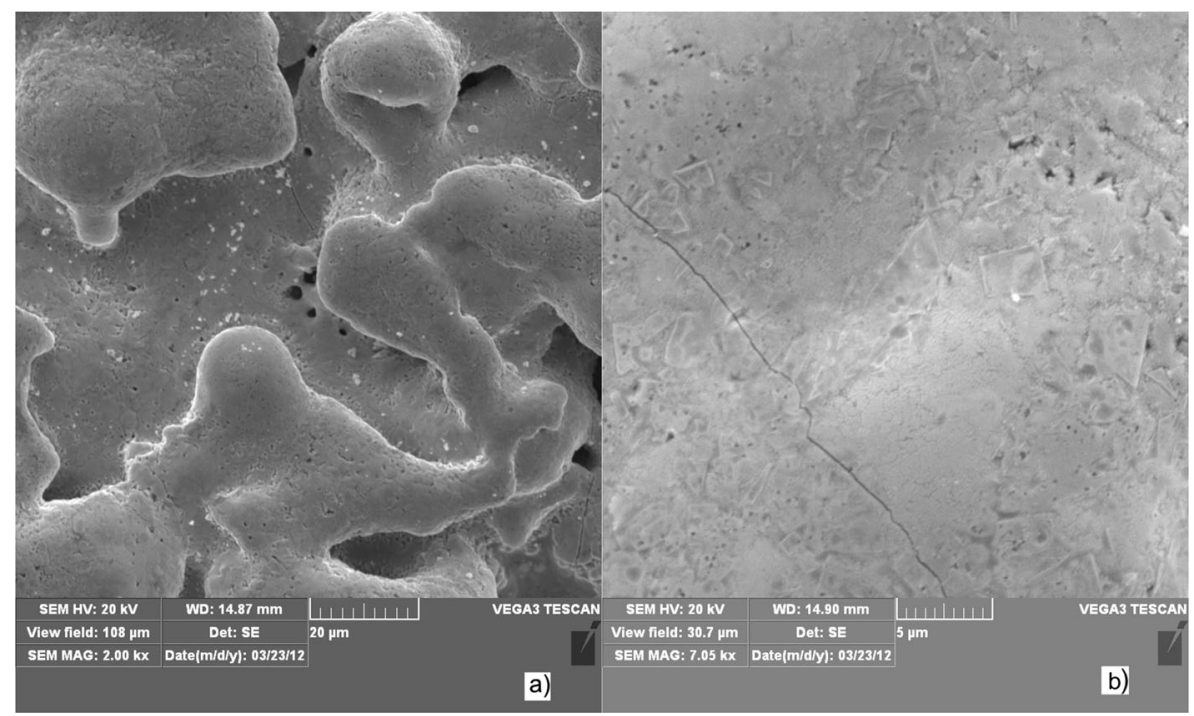

Fig. 4 SEM-micrograph images of the fifth sintered layer

composition and the porosity of layers are interrelated which influence on hardness of coatings.

\section{Hardness of Multilayer Coatings}

Results of Hardness measurements are shown in Fig. 6 in compare to the phase composition. Each point on the plot represents hardness of the surface produced with different number of sintered layers in range from 1 to 10 . A step change in phase composition, as indicated by bars in Fig. 6, is responsible for steep hardness increases of first six layers with the peak value of $21 \mathrm{GPa}$. According to the investigations performed by Lakhothin et al. [1] the carbide $\mathrm{WC}$ and subcarbide $\mathrm{W}_{2} \mathrm{C}$ phases have

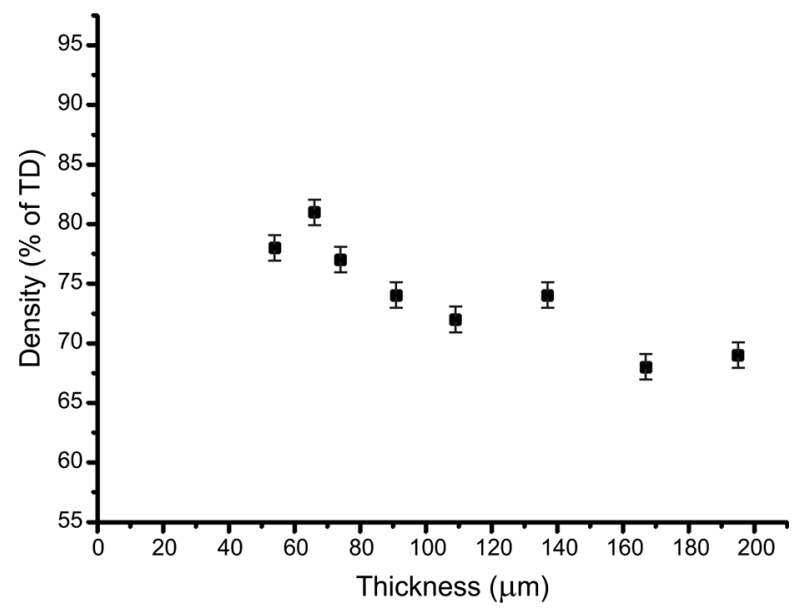

Fig. 5 Results of density measurements of hard metal multilayer coatings 


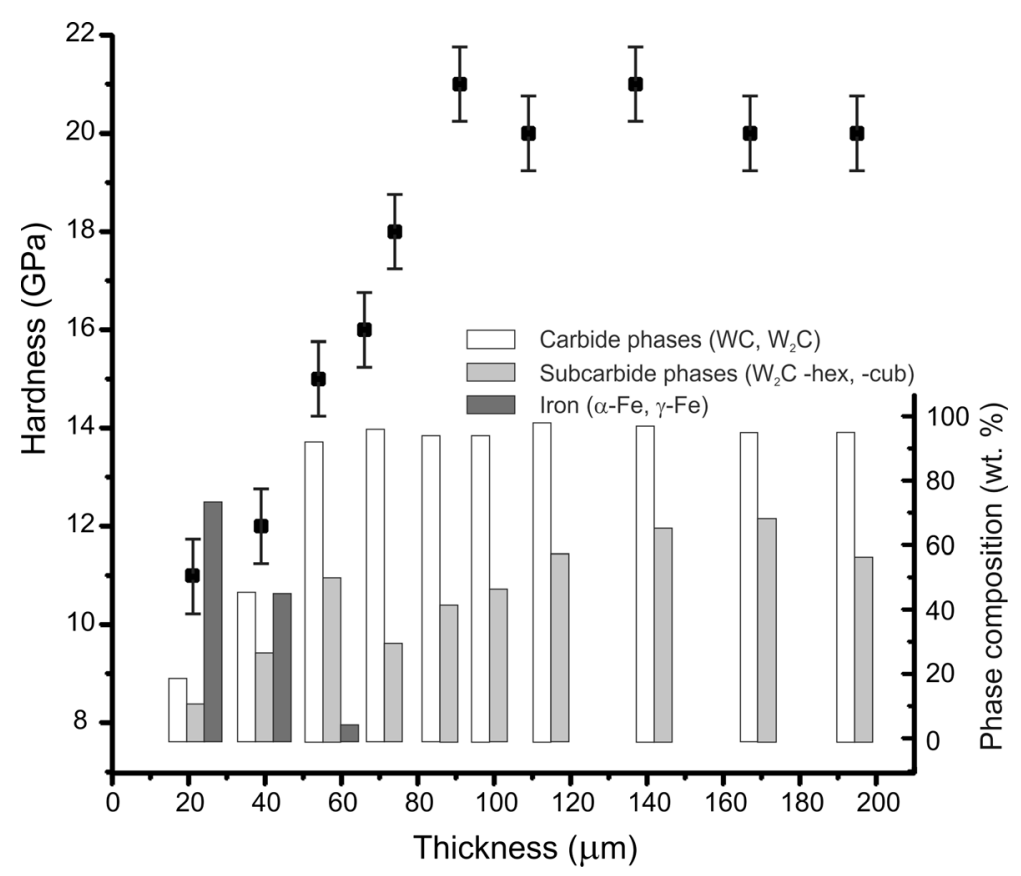

Fig. 6 Hardness of hard alloy multilayer coating. Hardness of each layer is shown by dots; bars under each dot present the phase composition of the layer

hardness of 24 and $35 \mathrm{GPa}$ respectively. Comparing between the hardness and the phase composition of sintered layers from 3 to 6 leads to the reasonable conclusion that the quantity of $\mathrm{W}_{2} \mathrm{C}$ phases (cubic and hexagonal) is responsible for layer hardness increases. And otherwise the remaining iron phases in layers from 1 to 3 are responsible for steep decrease in the hardness. Therefore, sintered in this study multilayer coatings have a gradient change in the phase composition and in the hardness.

\section{Abrasive Wear Tests Results}

Abrasive wear tests results of coatings with 4 sintered layers at loading conditions A (insufficient lubrication with alumina abrasive) and B (dry friction with silica sand abrasive) are summarized in Table 3. For comparison, Table 3 also shows the results of

Table 3 Abrasive wear resistance

\begin{tabular}{llclc}
\hline N & Material & Density, $\%$ TD & Loading scheme & Deterioration, $\mu \mathrm{m}^{3} /(\mathrm{N} \cdot \mathrm{m})$ \\
\hline 1 & Hard metal coating 4 layers & 80 & A & 24 \\
2 & Compacted WC-10 \%Co alloy & 100 & A & 20 \\
3 & Steel Fe-0,45 \%C & 100 & A & 880 \\
4 & Hard metal coating 4 layers & 80 & B & 55 \\
5 & Steel Fe-0,45 \%C & 100 & B & 2700 \\
6 & Compacted WC-10 \%Co alloy & 100 & B & 42 \\
\hline
\end{tabular}


abrasive wear tests of parts made of hard metal alloy WC-10 \% Co, produced by powder metallurgy, and steel $\mathrm{Fe}-0.45 \% \mathrm{C}$ parts, which were hardened and tempered to the hardness 45 HRC. According to the data in Table 3, properties of hard metal coatings are comparable with items made of compact hard alloy WC-10\% Co and considerably surpass wear resistance of parts, made of hardened Fe- $0.45 \% \mathrm{C}$ steel. The main reasons for that are the high level of density, the hardness and the carbide phase content.

\section{Discussion}

It has been shown that the dense hard metal coatings can be produced by short-pulse laser sintering. The entire process may be described as a SLM technique, but the shortpulse mode gives very high power density which leads to the rapid temperature rise over the melting point of tungsten carbide. High temperatures and special scanning strategy allow to produce coatings with high quality in the terms of roughness, abrasive wear resistance, hardness and density. As hard metal powders are very expensive, their coatings should be smooth and have good properties. Roughness of sintered coatings can be reduced by an appropriate choose of the processing parameters, which minimizes 'balling effect' and distortions due to thermocapillary forces which is good for post-processing [11].

Thus, the short pulse laser sintering allows obtaining high-density gradient coatings with the gradual change in the phase composition and properties from layer to layer. First two sintered layers contain $\alpha$ - and $\gamma$-phase of iron giving good adhesion strength between the coating and the substrate, whereas the outer layers have high hardness because they are saturated by tungsten carbide and subcarbide phases. Determination of the adhesion strength between the coating and the substrate using a normal fracture method leads to the conclusion that the adhesion strength is more than the breaking strength of the coating. To demonstrate this property an image of a coating after a shock action by a sharp hard indenter with the kinetic energy of $2 \mathrm{~J}$ is shown in Fig. 7a. The kinetic energy is sufficient to break through the entire thickness of the coating, which was $120 \mu \mathrm{m}$, and cause the considerable plastic deformation of the substrate to depth of about $1 \mathrm{~mm}$. As a result of the indenter penetration, there is a displacement of the considerable volume of metal towards to the edge of hole and to the surface of the

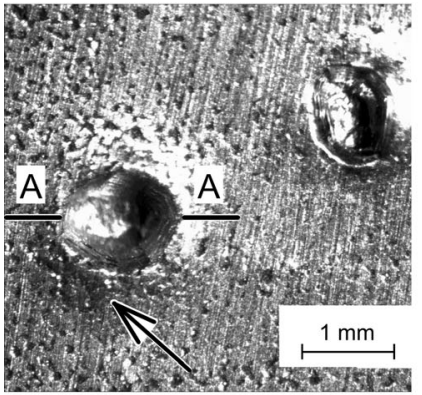

(a) $\times 40$

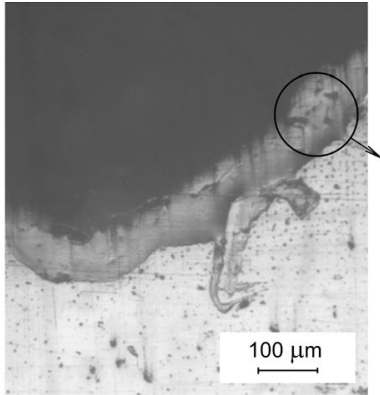

(b) $\times 250$

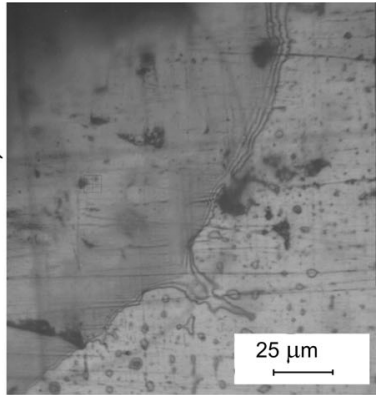

(c) $\times 1000$

Fig. 7 Areas of plastic deformations of the coating with thickness $120 \mu \mathrm{m}$ after indenters shock action. The arrow indicates the starting place of the plastic deformation in which the metal flows up from the surface 
sample which may be described as a plastic flow of metal. It is clearly seen in Fig. 7a that such impact does not lead coating to have cracks or exfoliation. Contrariwise, the coating with hardness $20 \mathrm{GPa}$ plastically deformed together with the substrate. The cross section, made in plane A-A of the impact zone, which is marked in Fig. 7a, clearly demonstrates this ability. Figure $7 \mathrm{~b}$ shows, that there is no exfoliation of the coating, but microcracks in hard outer layers are registered. Such behavior might be explained by relatively softer inner layers, which gives good adhesion strength. Figure $7 \mathrm{c}$ shows appearance of periodic structures with a wave nature in the interface between the substrate and the coating, probably caused by severe plastic deformations during shock impact. An introduction of the indenter with the same kinetic energy into a substrate without coating gives deformation to depth of about $2 \mathrm{~mm}$.

In our experiments, the laser power was set to the maximum value $(50 \mathrm{~W})$ but extremely high energy density was obtained due to short time of pulse (about $10 \mathrm{~ns}$ ). Further decreasing time of a laser impulse may not lead to better density of the coating because there would be insufficient time for heat transfer from the irradiated zone which will lead to overheating of local area and sufficient evaporation of the material.

\section{Conclusion}

Our experimental results show the possibility of obtaining hard metal coatings by the process variant to Selective Laser Melting, using a laser, operated in a short pulse mode. The coatings have functional properties such as hardness and abrasive wear resistance which are comparable to the solid WC-10\% Co parts made by powder metallurgy. The hardness of the coatings achieves $21 \mathrm{GPa}$. Careful selection of processing parameters allows to form dense coatings with gradual change in phase composition. The coatings properties are characterized by the high adhesion strength to the substrate because of relatively soft inner layers, but very hard outer layers explain a high value of achieved wear-resistance. The presence of residual porosity does not allow using the coatings for cutting tools but the technique is efficient for parts which operate in abrasive wear condition with high contact pressure and shock loads. Results of investigation may be put into the commercial practice by coating of such parts as thread-rolling heads, punches, contact surfaces, rock augers, etc. After the fifth sintered layer, the phase composition and density became stable, which allows to use the processing technique for complex 3D objects manufacturing by layer-wise powder based process such as SLM.

Acknowledgments The author would like to thank for the financial support the Ministry of Education and Science of Russia under the program 07.08 “Applied Research in Education” project № 2049 and the Russian Foundation for Basic Research (RFBR) project № 14-29-10282.

\section{References}

1. Lakhotkin, Y.V., Kuzmin, V.P., Goncharov, V.L.: Hard corrosion-resistant coatings for constructional applications. J. Protect. Met. Phys. Chem. Surf. 45, 833-837 (2009) 
2. Savarimuthu, A.C., et al.: Sliding wear behavior of tungsten carbide thermal spray coatings for replacement of chromium electroplate in aircraft applications. J. Therm. Spray Tech. 10(3), 502-510 (2001)

3. Wang, X.C., Laoui, T., Bonse, J., Kruth, J.P., Lauwers, B., Froyen, L.: Direct selective laser sintering of hard metal powders: experimental study and simulation. Int. J. Adv. Manuf. Technol. 19, 351-357 (2002)

4. Maeda, K., Childs, T.H.C.: Laser sintering (SLS) of hard metal powders for abrasion resistant coatings. J. Mater. Process. Technol. 149, 609-615 (2004)

5. Dubourg, L., St-Georges, L.: Optimization of laser cladding process using Taguchi and EM methods for MMC coating production. J. Therm. Spray Technol. 15(4), 790-795 (2006)

6. Techel, A., Luft, A., Muller, A., Nowotny, S.: Production of hard metal-like wear protection coatings by $\mathrm{CO}_{2}$ laser cladding. Opt. Quant. Electron. 27, 1313-1318 (1995)

7. Laser in Manufacturing. Ed. J. Paulo Davim, p. 33-34 (2012)

8. Picas, J.A., Xiong, Y., Punset, M., Ajdelsztajn, L., Forn, A., Schoenung, J.M.: Microstructure and wear resistance of $\mathrm{WC}-\mathrm{Co}$ by three consolidation processing techniques. Int. J. Refract. Met. Hard Mater. 27, 344-349 (2009)

9. Morgan, R., Sutcliffe, C.J., O’Neil, W.: Density analysis of direct laser remelted 316 stainless steel cubic primitives. J. Mater. Sci. 39, 1195-1205 (2004)

10. Kharanzhevskiy, E.V., Krivilyov, M.D.: Laser sintering of Fe-Ni nanocomposites. Phys. Met. Metallogr. 111(1), 53-61 (2011)

11. Kharanzhevskiy, E.V., Ipatov, A.G., Nikolaeva, I.O.: Influence of processing parameters on the density of hard-metal primitives obtained by short pulse selective laser sintering. Bull. Udmurt Univ. 4(2), 14-21 (2014). in Russian

12. Kostenkov, S.N., Kharanzhevskii, E.V., Krivilev, M.D.: Determination of characteristics of laser radiation interaction with nanocomposite powder materials. J. Phys. Met. Metallogr. 113(1), 93-97 (2012)

13. Kruth, J.P., Froyen, L., Van Vaerenbergh, J., Mercelis, P., Rombouts, M., Lauwers, B.: Selective laser melting of iron-based powder. J. Mater. Process. Technol. 149, 616-622 (2004) 